\title{
Trends in ageing and ageing-in-place and the future market for institutional care: scenarios and policy implications
}

\author{
PETER ALDERS* \\ Erasmus School of Health Policy and Management, Erasmus University, Rotterdam, The Netherlands \\ FREDERIK T. SCHUT \\ Erasmus School of Health Policy and Management, Erasmus University, Rotterdam, The Netherlands
}

\begin{abstract}
In several OECD countries the percentage of elderly in long-term care institutions has been declining as a result of ageing-in-place. However, due to the rapid ageing of population in the next decades future demand for institutional care is likely to increase. In this paper we perform a scenario analysis to examine the potential impact of these two opposite trends on the demand for institutional elderly care in the Netherlands. We find that the demand for institutional care first declines as a result of the expected increase in the number of low-need elderly that age-in-place. This effect is strong at first but then peters out. After this first period the effect of the demographic trend takes over, resulting in an increase in demand for institutional care. We argue that the observed trends are likely to result in a growing mismatch between demand and supply of institutional care. Whereas the current stock of institutional care is primarily focussed on low-need (residential) care, future demand will increasingly consist of high-need (nursing home) care for people with cognitive as well as somatic disabilities. We discuss several policy options to reduce the expected mismatch between supply and demand for institutional care.
\end{abstract}

Submitted 5 October 2016; revised 6 September 2017; accepted 16 February 2018; first published online 21 May 2018

\section{Introduction}

Faced with an ageing population, in many countries matching future supply and demand (or need) for long-term care (LTC) challenges governments. Key questions include safeguarding an adequate provision of formal and informal care and an adequate supply of institutional and home care facilities that is affordable to those in need

\footnotetext{
*Correspondence to: Peter Alders, PhD, Erasmus School of Health Policy and Management, Erasmus University, P.O. Box 1738, 3000 DR Rotterdam, The Netherlands. Email: alders@eshpm.eur.nl
} 
Table 1. Share of $80+$ population in care homes in various OECD countries $(\%)$

\begin{tabular}{lcc}
\hline \hline Country & Year 2000 & Year 2015 \\
\hline The Netherlands & $21.6^{\mathrm{a}}$ & $16.0^{\mathrm{b}}$ \\
Sweden & 20.9 & 13.1 \\
Switzerland & 20.7 & 16.9 \\
Norway & $16.0^{\mathrm{c}}$ & 13.5 \\
Denmark & $14.8^{\mathrm{d}}$ & $12.7^{\mathrm{b}}$ \\
Canada & 12.9 & 10.8 \\
Germany & 12.7 & 11.6 \\
Japan & $9.2^{\mathrm{e}}$ & $7.4^{\mathrm{f}}$ \\
\hline \hline
\end{tabular}

Source: OECD (2017).

a2004

${ }^{\mathrm{b}} 2014$

${ }^{\mathrm{c}} 2001$

$\mathrm{d}_{2006}$

e 2002

$\mathrm{f}_{2016}$

for LTC. Forecasting the need for home care and institutional LTC is all but straightforward, however, due to diverging trends in ageing and ageing-in-place. ${ }^{1}$

The trend of ageing-in-place seems to be partly driven by technological advancement, changing preferences and culture, and partly by changes in health policy (Alders et al., 2017). Personal emergency systems have given a sense of safety and ease notifying caregivers to act swiftly when needed (De San Miguel and Lewin 2008). Preferred alternatives, most notably home-delivered care and assisted living, were likely filling the gap left by declining nursing home use in the United States (Bishop, 1999; Stevenson and Grabowski, 2010). ${ }^{2}$ The trend of ageing-in-place, with a steadily declining percentage of people aged over 80 years in LTC institutions is noticeable in several OECD countries (see Table 1).

The trend of deinstitutionalization is especially noticeable in countries with traditionally relatively high shares of institutionalized elderly. In countries where traditionally the family has been the main provider of care of the elderly, like in Southern and Eastern Europe or Korea, the level of institutionalized elderly has always been low and in some countries might be increasing.

As the number of people over 80 years will double over the next 20 years, however, in the future the declining demand for institutional LTC due to ageingin-place might be offset by a growing population in need for institutional LTC. The effect of population ageing on the demand for institutional LTC might be

1 Ageing-in-place can be defined as 'remaining living in the community with some level of independence, rather than in care homes' (Davey et al, 2004).

2 Stevenson and Grabowski (2010) find that a $10 \%$ increase in assisted living capacity led to a $1.4 \%$ decline in private-pay nursing home occupancy and a $0.2-0.6 \%$ increase in patient acuity. 
somewhat mitigated by a compression of morbidity (i.e. a reduction of the time spent by elderly in worse health or disability) but the empirical evidence about this is mixed. Chatterji et al. (2015) found in a review of the literature some evidence for compression of morbidity if morbidity was defined as a form of disability or impairment, but evidence for the opposite if morbidity is defined as multiple diseases.

Not only the quantity but also the type and quality of institutional care that will be demanded is likely to change, because of changing ideas, expectations and preferences of how institutional care should be provided. Traditionally, institutional care for impaired elderly was hospital-like and clinically oriented. Many LTC institutions were built in the late 70s and early 80 s and were based on hospital design, with semi-private rooms and cafeteria-style dining options (Gerace, 2012). For more than a decade, however, the delivery of institutional LTC is shifting to a home-like environment in a nursing home (Moise et al., 2004; White-Chu et al., 2009; Koren, 2010; Grabowski et al., 2014; Miller et al., 2016). For dementia care, the trend over the past two decades has been to reduce the size of the nursing 'unit' from 60 beds to households accommodating anywhere between 9 and 24 residents (Calkins, 2009). Smaller units appear to have a number of positive benefits such as higher motor functioning; greater friendship formation; less anxiety, sadness and depression; more positive activity involvement; and greater mobility (Calkins, 2009).

In this paper, we analyse the changing demand for institutional LTC in the Netherlands using three scenarios based on different assumptions about future changes in the need for institutional care. By comparing the future composition of the institutionalized population with the current stock of institutional care facilities we identify the potential gap between future supply and demand. ${ }^{3}$ We discuss several policy options to reduce the expected mismatch between supply and demand for institutional care. The Netherlands constitutes an interesting case study since in this country the international trend of deinstitutionalization is especially prominent given the high level of institutionalization (see Table 1) and recent reforms to reinforce the trend of ageing-in-place (Alders et al., 2015).

\section{LTC in the Netherlands}

The Netherlands has a separate tax-based system of social insurance for institutional LTC (abbreviated as WLZ). Access to institutional care is restricted to citizens that need permanent supervision or need a sheltered residence (Ministry of Health, Welfare and Sport, 2014). Once someone is admitted to institutional care, he or she can choose to live in an institution or arrange housing him- or herself. ${ }^{4}$

3 We disregard elderly people with a mental handicap or a psychiatric disorder, representing about $11 \%$ of the elderly in institutional care.

4 People who arrange housing themselves pay a lower co-payment to account for that. 
Table 2. Number of people using institutional care per care severity package (ZZP), 2014

\begin{tabular}{lr}
\hline \hline ZZP 1: Assisted living with some support & 1490 \\
ZZP 2: Assisted living with support or personal care & 5490 \\
ZZP 3: Assisted living with support and intensive personal care & 13,410 \\
ZZP 4: Assisted living with intensive support and extensive nursing & 26,065 \\
ZZP 5: Nursing home care with extensive dementia care & 50,600 \\
ZZP 6: Nursing home care with extensive personal care and nursing & 25,975 \\
ZZP 7: Nursing home care with intensive care, with focus on supervision & 14,550 \\
$\quad$ (often behavioural problems) & 2770 \\
ZZP 8: Nursing home care with intensive care, with focus on personal care/nursing & 140,350 \\
$\quad$ (problems with ADL and cognitive) & \\
Total number of users ZZP 1-8 & \\
\hline \hline
\end{tabular}

Source: Statistics Netherlands (2017a).

Note: $\mathrm{ADL}=$ activities of daily living.

${ }^{\text {a }}$ Reference date is the fourth quarter of 2014.

Total cost for a person in a nursing home is on average about 79,000 euro per year (Ministry of Health, Welfare and Sport, 2016).

Providers of institutional care covered by the public LTC insurance scheme are non-profit organizations by law. They are paid on the basis of a bundled payment per client based on an assessment of need by an independent agency (CIZ). Based on this assessment eligible people are entitled to a certain 'care severity package' (in Dutch abbreviated as ZZP). The bundled payment per ZZP includes a payment for the capital costs (i.e. the normative housing component, NHC), for the provision of care and for 'hotel services' like meals, entertainment and house cleaning. Eligible people can be entitled to one out of eight different ZZPs with increasing care needs (see Table 2). ${ }^{5}$

In general, elderly people with relatively lower care needs (ZZP 1-3) reside in residential care homes and those with high care needs (ZZP 5-8), who require more intensive care and treatment, in nursing homes, although this division has blurred during the last decades. People who are entitled to care package ZZP4 ('Assisted living with intensive support and extensive nursing') are at the boundary of residential and nursing home care. Two care packages are suited for people with - primarily - somatic impairments (ZZP 4 and 6) and three care packages are meant for people with - primarily - cognitive impairments (ZZP 5, 7 and 8). Elderly people with dementia generally live in nursing homes, often in a form of group-living.

The procurement of care included in the various care packages is carried out by regional care offices, which are separate legal entities operated by the largest health insurer in that region. For this procurement, the Netherlands is divided in

5 There are two other ZZPs (for rehabilitation and palliative care) which are not relevant for our analysis and therefore not taken into account. 
31 regions, each with a legally determined annual budget constraint. Per region on average 25 organizations are active in providing institutional care (Dutch Healthcare Authority, 2013). Whether clients can choose the LTC institution of their first choice does not only depend on the institution's capacity but also on the amount of care purchased by the regional care office. The regional care office may take into account the quality of care homes and the preferences of the clients in that region, but there is no guarantee that these preferences will be matched. There does not seem to be excess demand: whereas in 2014 140,350 persons were living in a LTC institution (Table 1), on September 2013 the waiting list for institutional care consisted of only 120 people (Ministry of Health, Welfare and Sport, 2013a).

\subsection{Demand for care bome places}

The percentage of elderly in institutional care declined since 1980; whereas $63 \%$ of the people older than 80 years lived in an institutional setting in 1980, by 2014 that percentage had dropped to $16 \%$ (Ministry of Health, Welfare and Sport, $2013 \mathrm{~b}$ and Table 1). In recent years, the number of users of institutional care dropped by about $2.7 \%$, from 144,315 in 2012 to 140,350 in 2014 (Statistics Netherlands, 2017a). This decline was concentrated in the low-need care packages (ZZP 1-3) as the number of elderly in institutional care entitled to these ZZPs declined by $45 \%$. By contrast, the number of institutionalized elderly entitled to a higher care severity packages [(ZZP $4-8)$ grew by $11 \%$ ].

Admission to a LTC institution is generally related to concerns about safety for a person (for instance a fall) or for his or her environment (for instance a risk of causing a fire accident or a frail spouse) and the inability to guarantee personal hygiene. ${ }^{6}$ Gaugler et al. (2007) suggest that once certain functional or cognitive thresholds are reached, risk of nursing home admission increases substantially. In the Netherlands, factors such as age, disability, receiving formal care with household tasks or personal care, a hospital visit in the last 6 months and dementia were significant predictors of admission to an LTC institution (Alders et al., 2017). A significant 'time' effect was found as well: in the period 2006-2009 less people were admitted to institutional care compared to the period 1995-1999 when they were in a comparable health and personal situation. Elderly with mild disability are more likely to be treated at home than before, whereas severely disabled individuals continue to receive institutional LTC. Overall, the effect of ageing-in-place was dominant in the period 1996-2009 (de Meijer et al., 2015; Alders et al., 2017).

The decreasing number of places in institutional care is mirrored by an increasingly more disabled and older population in LTC institutions (de Klerk, 2011). The percentage of people with severe disabilities increased from slightly

6 Such limitations mirror the functions that LTC institution provide and that are difficult to fulfil at home: 24 hour unplanned care, continuous supervision to ensure a safe, clean and organized place, specialized care concerning activities of daily living (ADL), instrumental ADL or chronic diseases, and company of other people. 
more than $40 \%$ in 2000 to almost $50 \%$ in 2008 . As a consequence, the decline in the percentage of living in LTC institutions is coinciding with a shift from residential care to care in psychogeriatric nursing homes (de Klerk, 2011).

A couple of recent policy measures are likely to affect the demand for institutional care in the near future. First, in 2013, more strict admission criteria were implemented. New clients with impairments comparable to the low-need care packages are no longer entitled to institutional care. Next, in 2013 and 2015, co-payments for institutional care increased in absolute and relative terms to home care. Since 2013, co-payments depend on someone's assets, with an exemption of the value of a house. In 2015 a major LTC reform 2015 took place, targeted at reinforcing the trend of ageing-in-place. A result of the reforms is that, since 2015, a co-payment is no longer required for home care in the form of district nursing, which may make home care financially more attractive. $^{7}$

Taking into account trends in ageing, socioeconomic factors and health status, Eggink et al. (2017) expect that the main driver of future growth in institutional care will be demography. For the period 2014-2030, they project that residential care increases annually by $2.1 \%$, which is a net effect of demography $(2.8 \%)$ and uptake per demographic group $(-0.8 \%)$. The lower uptake per demographic group is partly the result of an expected compression of years with disability $(-0.4 \%)$. This compression of disability is based on van Duin and Stoeldraijer (2014), who extrapolates trends on life-expectancy and self-reported disability of Statistics Netherlands of the period 1983-2012. The finding by van Duin and Stoeldraijer, however, is at variance with findings from other research and when other time periods are used (Statistics Netherlands, 2017b). In the period 1990-2008 prevalence rates of chronic diseases increased in community-living older people, whereas prevalence rates of activity limitations were stable or slightly decreased depending on the definition (Hoeymans et al., 2012). Other research showed an increase in the prevalence of mild activity limitations, but not in severe activity limitations in the Dutch older population over the period 1992-2009 (van Gool et al., 2011; Galenkamp et al., 2012).

\subsection{Supply of care bome places}

The number of places in institutional care declined from 183,000 in 1995 to 161,000 in 2010 (Statistics Netherlands, 2017c, 2017d). Although exact data on the capacity of institutional care in 2014 are not available, we estimate the institutional capacity at 146,000 places in 2014 by taking the available capacity in $2010(161,000)$ and subtracting the net decline of 15,000 places over the period 2010-2014 as derived from the annual reports of care organizations (DIGI MV, 2016). These numbers include a shift to more intensive care. From 1995 to 2010 the number of places in elderly facilities for low-need LTC decreased by about

7 Notice, however, that the price-elasticity of institutional care might be low (Reschovsky, 1998). 
$30 \%$ from 128,000 to 89,000 , while the number of places in elderly facilities for high-need care increased by about $30 \%$ from 55,000 to 72,000 (Statistics Netherlands, 2017c, 2017d). However, the former clear-cut distinction between low-need LTC in residential care facilities and high-need LTC in nursing homes has disappeared. According to a government website (www.zorgopdekaart.nl), in 2014 there were about 99,000 places in residential care facilities, although in many of these facilities elderly also receive high-need LTC. Of these 99,000 places, 33,650 cannot be reoriented towards high-need LTC covering costs. Total (potential) supply of high-need institutional care is therefore 112,350 places.

In 2016, 341 providers of institutional care and home care managed 386 nursing homes, 789 residential facilities and 259 combined locations in the Netherlands (Actiz, 2016a). ${ }^{8} 80 \%$ of the population in the Netherlands has a nursing home or residential care facility within $5.2 \mathrm{~km}$ (Riedel and Kraus, 2011). The association of LTC providers Actiz concluded from a survey among its members that 150-200 LTC institutions with a total capacity of about 10,000 elderly, were closed in the period 2013-2016. About half of the responding members are renting rooms that are idle in the private market (Actiz, 2016b). ${ }^{9}$

Until 2009, the government regulated the supply of institutional care by requiring a permit for building new facilities. When a permit was issued, providers were reimbursed for $100 \%$ of the actual capital costs. Since 2012, however, providers of institutional care have become increasingly at risk for the capital costs. In 2012 the reimbursement percentage of capital costs was lowered to $90 \%$, and in subsequent years stepwise further reduced to $0 \%$ in 2018. At the same time the percentage based on a NHC is proportionally increased. ${ }^{10}$ From 2018 on, the capital costs will be part of the negotiable price of a ZZP.

\section{Scenario analysis}

As argued above, two opposite forces primarily determine the future demand for institutional care. On the one hand, the long-term trend of ageing-in-place and recent measures of the Dutch government are expected to reduce the demand for institutional care. On the other hand, however, the ageing of the population is likely to result in a higher number of potentially frail elderly in need of institutional care. Furthermore, because the disability level is a key predictor of institutional use, the future expansion or compression of the period elderly are confronted with disabilities, is likely to have a major impact on the length of stay and thereby the future demand of institutional care.

8 These figures concern members of the association of LTC providers Actiz. These providers cover $90-95 \%$ of the market for institutional care.

9 The revenues for renting rooms to clients entitled to institutional care is usually significantly higher than for renting the same room in the private market (Olde Bijvank, 2015).

10 In 2016 the NHC is about 900 euro per month per client with a slightly higher NHC for higher ZZPs. 
We therefore distinguish the following three primary drivers of change in the use of institutional LTC:

1. Population ageing;

2. Disability levels;

3. Ageing-in-place: later admission to institutional care given a disability level.

\subsection{Methods}

There is a strand of literature using cell-based or macro-simulation models to make projections of likely demand for LTC for older people under different scenarios (Comas-Herrera and Wittenberg, 2003; Worrall and Chaussalet, 2015). Following Rothgang (2003), we calculate the future number of beneficiaries for a care package $\left(N_{k}\right)$ for a given year by taking the sum of the products of age- and gender-specific care probabilities for this care package $\left(P_{i j k}\right)$ with the respective population figures $\left(A_{i j}\right)$.

$$
N_{k}=\sum_{i} \sum_{j} P_{i j k} A_{i j}
$$

with $i=1,2$ sex, $j=$ age category $(0-20,20-35,35-50,50-65,65-70,70-75$, $75-80,80-85,85-90,90+)$; and $k=$ care severity package $1,2,3, \ldots, 8$.

The gender-specific care probabilities per age band are based on the use of institutional care severity packages in 2014 as reported by Statistics Netherlands (2017a) (Figure 1).

We simulate three scenarios, based on the three drivers of institutional LTC identified above, to calculate future use of institutional care over the period 2014-2035. These scenarios are summarized in Box 1.

The first scenario, labelled 'Ageing', only takes into account the population projections of Statistics Netherlands (2017e) and assumes that the age-related probabilities for admission to an institutional LTC facility stay constant. In 2014, the Netherlands had 16.8 million inhabitants; 2.92 million of them were older

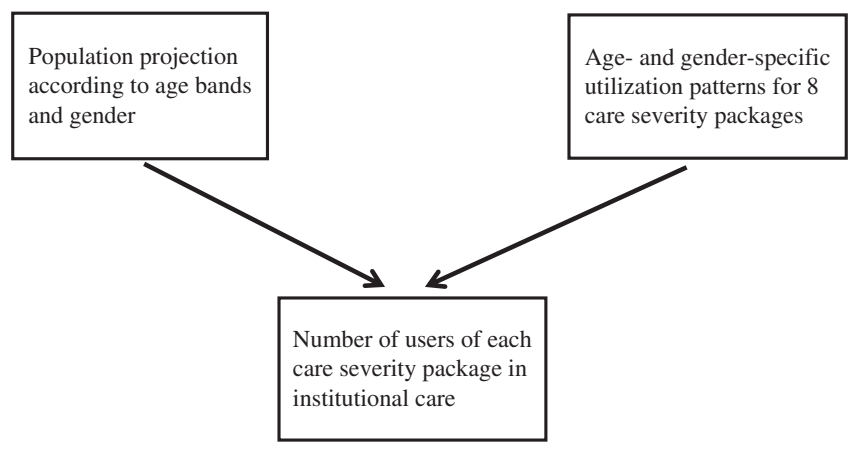

Figure 1. Graphic representation of the model 
Box 1. Scenarios for future demand of institutional long-term care (LTC).

- Scenario 1, 'Ageing': the proportion of older people receiving institutional care remains constant for each sub-group defined by age, gender and care severity package.

- Scenario 2, 'Improved health': admission to an institutional care facility is postponed by the same number of years as the increase in average life expectancy at 65 .

- Scenario 3, 'Reinforced ageing-in-place': admission to an institutional care facility is postponed by the same number of years as the increase in average life expectancy at 65 , and the average length of stay in an institution decreases linearly, in total by 6 months (from 36 to 30 months) over the period 2014-2035.

than 65 years and 0.72 million were older than 80 years (Statistics Netherlands, 2017c). Of the residents in institutional care $30 \%$ were aged above $90,48 \%$ between 80 and $90,18.5 \%$ between 65 and 80 , and $3.5 \%$ below 65 years. Using a prognostic model, with yearly updates for trends in birth death and migration, Statistics Netherlands forecasts that in 20354.5 million people are older than 65 years, and 1.4 million older than 80 years (Statistics Netherlands, 2017e).

In the second scenario, labelled "Improved health", we use the population projections of scenario 1 , and, given the mixed evidence on compression and expansion of morbidity, furthermore assume that the probabilities of using institutional care shift by 1 year for every year of life expectancy gained. For instance, the probability of admission to an institutional care facility for a 70-year-old woman is attributed to a 71-year-old woman in the year in which female life expectancy (at the age of 65) has risen by 1 year above base year female life expectancy: $P(X)_{t}=P(X+\varepsilon)_{t+1}<=>\mathrm{LE}_{t+1}-\mathrm{LE}_{t}=\varepsilon$ (see Rothgang, 2003). ${ }^{11}$ Drivers of this scenario could be, for instance, better life-styles or improved medical treatment methods. In the third scenario, labelled 'Reinforced ageingin-place', we use the trends in population ageing and disability levels of scenario 1 and 2 and, furthermore assume that the trend of ageing-in-place continues and the length of stay shortens. We assume that the average length of stay of people in an LTC institution declines from currently 36 months (3 years) to 30 months in 21 years over the period 2014-2035 (i.e. a reduction of $0.8 \%$ per year). To this end we assume that the probability of use of institutional care declines every year with $2 / 7$ month. ${ }^{12}$ Hence $P(\mathrm{X})_{t+i}=(1-y) \times P(X)_{t}$ with $y=(6 / 36 \times i / 21)$ and $i=1,2, \ldots 21$. Both the increased morbidity of residents and the significant decline in use of institutional LTC by the elderly point to a reduction of the length stay during the last decades. Data of Statistics

11 Because we use age bands, the probability of nursing home use for a person aged 78 years old after a 2 years gain in life-expectancy is determined for $3 / 5$ by the probability of the age band $75-80$ and for $2 / 5$ by the age band 70-75.

12 For reasons of simplicity, we assume a constant decline in length of stay. Another option would be to assume a function with an asymptotic decline of 6 months. 


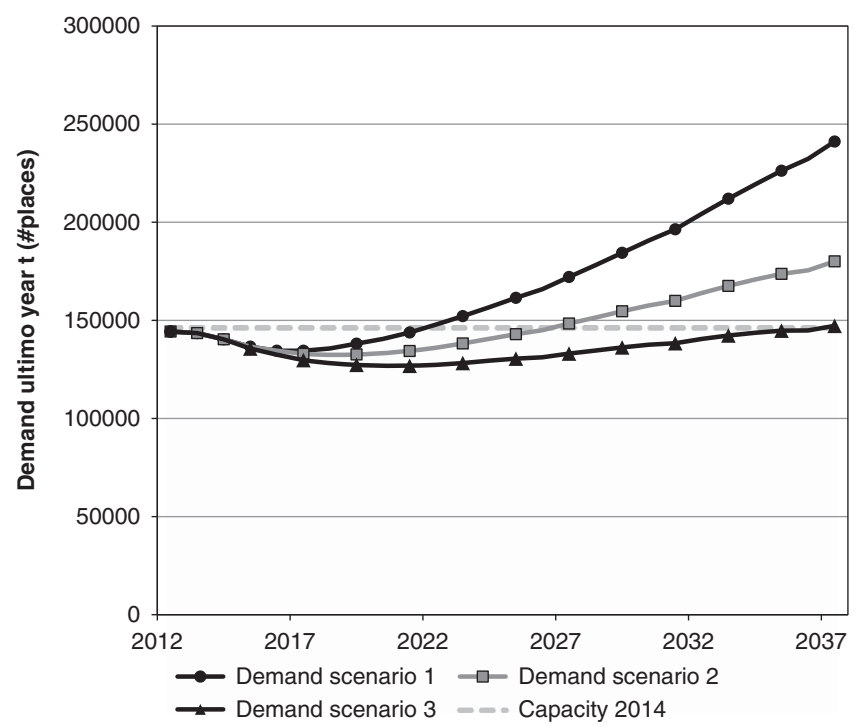

Figure 2. Three scenarios for the change in demand for institutional long-term care (LTC) facilities in number of places from 2012 to 2037, compared with the capacity of LTC facilities in 2014.

Netherlands (2017a) show that from 2012 to 2014 the average length of stay (from admission until death) for high-need persons has been reduced by $3.8 \%$. Nursing home care providers also draw attention to an increasingly severe caseload and a substantial reduction of the average length of stay (Kiers, 2016). Drivers of this scenario could be further technological changes and policies that facilitate and stimulate ageing-in-place (e.g. domotica, e-health), and stronger preferences for care at home.

As mentioned before, since 2013 new low-need elderly are no longer admitted to LTC institutional care facilities. People already admitted to institutional LTC keep their right on receiving nursing home care. Hence, the number of low-need elderly in nursing homes will steadily decline. Based on the data on length of stay of institutionalized elderly with low needs in 2012 and 2013 (Statistics Netherlands, 2017f), we assume that each year $35 \%$ of the low-need elderly will die or enrol in high-need care.

\section{Results}

We use 2014 as baseline year for the three scenarios to project future demand for institutional care. At the end of 2014 total excess supply of institutional care facilities was about 5650 places, being the difference between the estimated available total capacity $(146,000$ places) and the actual use (140,350 places, see Table 2). Despite the overall excess supply, however, there seems to be a qualitative mismatch: a shortage of rooms in (small scale) nursing homes of about 7600 
Table 3. Demand for institutional care (in number of places) for different need categories, according to three scenarios for the period 2014-2035.

Scenario 1: the proportion of older people receiving institutional care remains constant for each subgroup defined by age, gender and care severity package

\begin{tabular}{lrrrrrrr}
\hline & 2014 & $2016^{\mathrm{a}}$ & 2025 & 2035 & $\Delta$ '16-'14 & $\Delta$ '25-'14 & $\Delta$ '35-'14 \\
\hline Low-need & 20,390 & 8620 & 180 & 0 & $-11,770$ & $-20,210$ & $-20,390$ \\
High-need: somatic & 52,040 & 54,670 & 70,230 & 99,520 & 2630 & 18,190 & 47,480 \\
High-need: cognitive & 67,920 & 71,220 & 91,070 & 126,730 & 3300 & 23,150 & 58,810 \\
Total & 140,350 & 134,500 & 161,480 & 226,240 & -5850 & 21,130 & 85,890 \\
\hline
\end{tabular}

Scenario 2: admission to institutional care is postponed by the same number of years as average life expectancy at 65 years increases.

\begin{tabular}{lrrrrrrr}
\hline & 2014 & $2018^{\mathrm{a}}$ & 2025 & 2035 & $\Delta$ '18-'14 & $\Delta$ '25-'14 & $\Delta$ '35-'14 \\
\hline Low-need & 20,390 & 3640 & 180 & 0 & $-16,750$ & $-20,210$ & $-20,390$ \\
High-need: somatic & 52,040 & 55,860 & 61,760 & 75,130 & 3820 & 9720 & 23,090 \\
High-need: cognitive & 67,920 & 72,860 & 81,010 & 98,560 & 4940 & 13,090 & 30,640 \\
Total & 140,350 & 132,360 & 142,940 & 173,690 & -7990 & 2590 & 33,340 \\
\hline
\end{tabular}

Scenario 3: admission to institutional care is postponed by the same number of years as average life expectancy at 65 years increases and the length of stay gradually decreases over the entire period from 36 to 30 months

\begin{tabular}{lrrrrrrr}
\hline & 2014 & $2020^{\mathrm{a}}$ & 2025 & 2035 & $\Delta$ '20-'14 & $\Delta$ '25-'14 & $\Delta$ '35-'14 \\
\hline Low-need & 20,390 & 1540 & 180 & 0 & $-18,850$ & $-20,210$ & $-20,390$ \\
High-need: somatic & 52,040 & 54,280 & 56,370 & 62,610 & 2240 & 4330 & 10,570 \\
High-need: cognitive & 67,920 & 71,110 & 73,930 & 82,130 & 3190 & 6010 & 14,210 \\
Total & 140,350 & 126,930 & 130,480 & 144,740 & $-13,420$ & -9870 & 4390 \\
\hline \hline
\end{tabular}

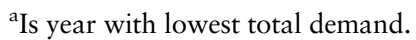

places for people with severe cognitive (and behavioural) problems and people with severe somatic disabilities. At the end of 2014, 119,960 people in institutional care were entitled to a high-need care severity package, whereas at the beginning of 2014 only 112,350 places for high-need institutional LTC were available.

The main results of the three scenarios are summarized in Table 3. In all scenarios the total demand for institutional care is likely to decline in the first years, reaching the lowest demand in 2016 (scenario 1), 2018 (scenario 2) and 2020 (scenario 3). As shown in Figure 2, however, in subsequent years this downward trend is reversed and demand will exceed the baseline capacity of institutional care facilities in 2022 (scenario 1), in 2027 (scenario 2) or will just match this in 2035 (scenario 3). Hence, the upward trend in demand for 


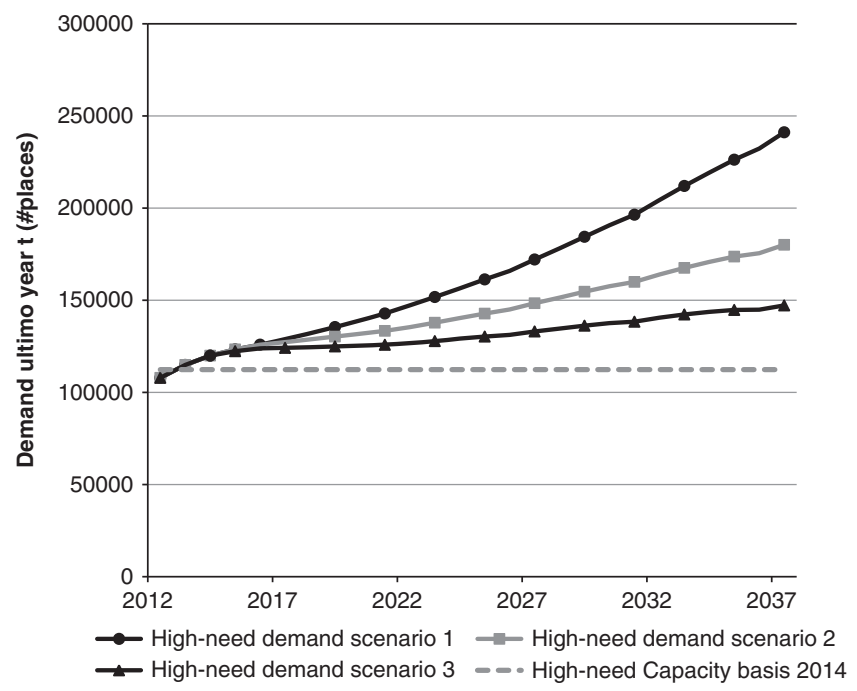

Figure 3. Three scenarios for the change in demand for high-need institutional long-term care (LTC) facilities in number of places from 2012 to 2037 compared with the capacity of highneed LTC facilities in 2014.

institutional LTC as result of population ageing may be partially or fully offset by healthy ageing and ageing-in-place, depending on the strength of these trends. The proportion of people over the age of 65 years in institutional care is $4.6 \%$ in 2014. In scenario 1 this proportion drops to $4.0 \%$ in 2021 and then increases to 4.7 in 2035. In scenario 2 it drops to about $3.6 \%$ in 2025 and then remains constant, while in scenario 3, it steadily declines to $3.0 \%$ in 2035 .

Figure 2 shows that if the trend of ageing-in-place is sufficiently strong, the existing capacity is sufficient to meet future demand if we only look to the number of available places. The limited change of total demand for institutional care, however, is hiding a more important and sizeable change in the composition of this demand. As shown in Table 3, in all three scenarios there is a substantial shift in demand from low-need to high-need institutional care, particularly for care for people with cognitive impairments. Figure 3 illustrates that the demand for high-need institutional care already exceeds the existing capacity of high-need LTC facilities in 2014, and that in all scenarios this gap will substantially increase over time if the high-need capacity will not be expanded.

Hence, providers are facing an increasing excess supply for low-need care and an increasing excess demand for high-need care.

\section{Discussion: policy options to counter the mismatch in demand and supply}

In this paper we projected the potential impact of ageing, changes in disability levels and changes in the length of stay in institutional care on the demand for 
institutional care. These changes are driven by changes in demography, population health, technology, social norms, policy reforms and relative prices of care. By distinguishing three scenarios we tried to capture the potential impact of several of these factors - primarily demography, population health, technology and ageingin-place policies - by a number of crude assumptions. Obviously, for this reason the scenarios provide merely a rough indication than a precise estimate of the future demand of institutional care.

We compare the projected future demand to current supply, to explore to what extent current supply is both qualitatively and quantitatively sufficient to meet future demand. At first sight, confronting total demand with the available baseline capacity, capacity problems do not seem to occur during the next 5-10 years, and might be tackled in the longer run by investments in healthy ageing and policies to reinforce ageing-in-place. A closer look, however, reveals a potentially growing gap between supply and demand for low-need and for high-need care, in particular for people with cognitive impairments. As a result of ageing-in-place and policy measures that restrict admission of low-need people to LTC institutions the demand for institutional care by low-need elderly will decline in the coming years. This will increase the already existing excess capacity of residential care. Because the current stock of institutional care is primarily suited for residential care, we observe a potentially growing qualitative gap between the available stock of institutional care and the needs of the growing number of people with high somatic and cognitive impairments.

Providers of residential care may attract other clients by providing assisted living, caring for people with dementia and intensive nursing home care. Moreover, spare capacity might be used for people who need low-cost housing. However, residential care facilities cannot be used automatically for nursing home care or small-scale dementia care (Heinen et al., 2012). The costs of the required adjustments (e.g. expanding bathrooms, including lifters, broadening doors) are estimated at 15,000-25,000 euro per unit (de Wildt and Neele, 2003; Nouws and Sanders, 2014).

In a competitive market, such mismatch between supply and demand is likely to be temporary: (new) providers will build new capacity or transform old capacity to address the mismatch. The market for institutional care has many properties of a potentially competitive market: capital costs are relatively low, new providers can enter with few beds, much care can be provided by relatively unskilled labor and the use of specialized equipment is small as compared to hospitals (Bishop, 1988). There are several reasons, however, why this market will not clear easily in case of excess supply. Return on investments in new facilities are highly uncertain, given the long-term nature of these investments (30-35 years), and because of the considerable uncertainties about the future role of the government and public financing, about the future demand including the scrap value of a facility, and about the projected labour supply shortages (Joldersma et al., 2017; van Aartsen, 2017). Moreover, excess supply might deter current providers to replace older 
facilities by newer ones that are better suited to accommodate higher need levels, as long as there is excess demand for high-need facilities and providers are not 'punished' for providing less suitable facilities.

In the past, the Dutch government basically regulated the capacity of institutional care by issuing permits for new capacity and a $100 \%$ reimbursement of capital costs. With the transition to a system where providers decide on the level of capacity and fully bear the risk of vacancies, competition may effectively reduce the potential mismatch between supply and demand. However, regulatory constraints at both the demand and supply side still may hamper the necessary adjustments of institutional LTC capacity. A first supply-side constraint is that LTC institutions require a license to provide care that is financed by the public LTC insurance scheme (WLZ) and are not allowed to distribute profits to owners/ shareholders. This may prevent investors entering the market and establishing new or adjusting existing facilities. ${ }^{13}$ In addition, LTC providers need government approval if they want to sell facilities on the private market. Next, capacity adjustments may be hampered by municipalities since they decide about the landuse planning for societal purposes, including the provision of nursing home and residential home care. A final supply constraint that reduces the attractiveness of investments in adjusting current facilities is the restriction that these facilities may only be rented to low-income persons if the building is the property of a housing corporation. At the demand side, total demand is constrained by regional budgets set by the government. Regional care offices decide how this budget is allocated and this allocation may not meet the preferences and needs of the residents (i.e. patients follow the money instead of money follows the patients).

Because of the considerable (regulatory) uncertainties and current demand and supply constraints, an adequate and timely adjustment of the projected (growing) quantitative and qualitative mismatch is unlikely without (a mix of) policy measures. At the demand side, the government can increase market competition by providing clients an individual-trailing budget (i.e. the money follows the patient) in order to let clients choose their preferred nursing home. At the supply side, the government may pursue policies to reduce the overcapacity of low-need residential care facilities. For instance, the government body responsible for organizing housing for refugee status holders may actively rent or buy buildings of residential care facilities with idle capacity. By taking outdated facilities out of stock, the business case for building new capacity improves, because the new capacity will not result in cannibalization of the revenue on the old facilities. Furthermore, the government may increase incentives for investors to invest in better facilities for the growing high-need population by allowing providers to distribute profits (i.e. by lifting the legal ban on profit distribution). Increasing these incentives, however, may also involve risks. Especially when quality

13 To some extent investors can circumvent the legal prohibition of distributing profits by requiring a high return on a subordinated loan. 
information is poor for-profit nursing homes may have stronger incentives to skimp on quality. Evidence from the United States shows that non-profit nursing homes may perform better than for-profit ones (Grabowski et al., 2008; Hirth et al., 2014). Therefore, improving information about quality of LTC is important when

the role of the market is reinforced to meet future consumer preferences about LTC provision. However, the current system of reporting on quality of LTC providers in the Netherlands, which is based on a so-called consumer-quality index, is not satisfactory and will be abandoned, but a new system still needs to be developed (Ministry of Health, Welfare and Sport, 2015). Werner et al. (2016) conclude that reporting quality by the nursing home star rating system in the United States significantly affected consumer demand for high- and low-rated nursing homes. Zhao (2016) finds that while the effect of competition on nursing home quality is generally rather limited, this effect becomes significantly stronger with increased information transparency. These results suggest that regulations on public quality reporting and market structure are policy complements, and should be considered together to guarantee an adequate future supply of institutional care facilities.

\section{Conclusion}

Due to opposite trends of ageing and ageing-in-place, LTC provision in the Netherlands likely has to grapple with an increasing mismatch between the demand and supply of institutional care. Future demand will increasingly consist of care for high-need elderly, whereas the current stock of care homes is better suited for relatively low-need elderly. As a result, both the existing overcapacity of lowneed care facilities and undercapacity of high-need facilities may increase. Hence, high-need elderly may be increasingly forced to use residential homes that are not suitable given their impairments. An option for the government to bring demand and supply more in balance is to abolish current regulatory constraints on demand and supply that appear to make LTC providers and potential entrants reluctant to invest in new capacity or to refurbish the existing capacity. By removing these constraints, however, the government may also increase the risk of market failure, such as moral hazard and quality skimping. Therefore, improving information about quality of LTC provision is imperative in case of a greater reliance on market forces to meet future preferences for LTC.

Many countries face the same trends of ageing and ageing-in-place and may be confronted with similar challenges to match future demand and supply of institutional LTC. The Dutch case shows the importance of differentiating care needs in forecasting future demand for institutional care, because the demand for institutional care in case of low-need and in case of somatic and cognitive high-need care might diverge. Looking at the market for institutional care from an aggregated point of view could miss a potentially severe mismatch between supply and demand, because of the rapidly changing composition of those who need 
institutional care. Of course, what we see as a potential mismatch now or in the Netherlands, might be perceived differently in the future or in other countries. Notwithstanding this, given the rapidly changing composition and preferences of elderly people for institutional LTC, projections of future demand for institutional care may provide useful information for an adequate adjustment of the future supply of publicly financed LTC facilities.

\section{Acknowledgment}

The authors would like to thank Roland Beukers, Henk Sijsling, Jolien Heinen and Ernst van Koesveld and three anonymous referees for helpful comments and Niek Stadhouders for data on institutional care. The authors acknowledge financial support through the Netspar grant on 'Optimal saving and insurance for old age: the role of public long-term care insurance'.

\section{References}

van Aartsen, C. (2017), 'Vrije vastgoedtarieven brengen zorg in gevaar', Zorgvisie, https://www.zorgvisie.nl/financien/nieuws/2017/3/korting-op-vergoeding-vastgoed-brengtzorg-in-gevaar-/ [20 August 2017].

Actiz (2016a), 'Feiten en cijfers over de verpleeghuiszorg', https://www.actiz.nl/stream/160715feiten-en-cijfers-verpleeghuiszorgdef.pdf [26 July 2017].

Actiz (2016b), Resultaten kwalitatieve analyse Leegstand Verzorgingshuizen, Utrecht.

Alders, P., H. Comijs and D. Deeg (2017), 'Changes in admission to long-term care institutions in the Netherlands: comparing two cohorts over the period 1996-1999 and 2006-2009', European Journal of Ageing, 14(2): 123-131.

Alders, P., J. Costa-Font, M. de Klerk and R. Frank (2015), 'What is the impact of policy differences on nursing home utilization? The cases of Germany and the Netherlands', Health Policy, 119(6): 814-820.

Bishop, C. E. (1988), 'Competition in the market for nursing home care', Journal of Health Politics, Policy and Law, 13(2): 341-360.

Bishop, C. E. (1999), 'Where are the missing elders? The decline in nursing home use, 1985 and 1995', Health Affairs, 18(4): 146-155.

Calkins, M. P. (2009), 'Evidence-based long term care design', NeuroRehabilitation, 25(3): $145-154$.

Chatterji, S., J. Byles, D. Cutler, T. Seeman and E. Verdes (2015), 'Health, functioning, and disability in older adults-present status and future implications', The Lancet, 385(9967): 563-575.

Comas-Herrera, A. and D. Wittenberg (eds.) (2003), European Study of Long-Term Care Expenditure, PSSRU Discussion Paper 1840, PSSRU, LSE Health and Social Care, London School of Economics.

Davey, J., V. Joux, G. de, Nana and M. Arcus (2004), Accommodation Options for Older People in Aotearoa/New-Zealand, Christchurch: Centre for Housing Research.

de Klerk, M. (2011), Zorg in de laatste jaren: gezondheid en hulpgebruik in verzorgings- en verpleeghuizen 2000-2008, The Hague: SCP. 
de Meijer, C., P. Bakx, E. Doorslaer and M. Koopmanschap (2015), 'Explaining declining rates of institutional LTC use in the Netherlands: a decomposition approach', Health economics, 24(Supplement 1): 18-31.

De San Miguel, K. and G. Lewin (2008), 'Personal emergency alarms: what impact do they have on older people's lives?', Australasian Journal on Ageing, 27(2): 103-105.

de Wildt, R. and J. Neele (2003), Scenario's Verzorgingshuizen, Amsterdam: RIGO.

DIGI MV (2016), https://www.jaarverslagenzorg.nl/zorginstellingen [10 June 2016].

Dutch Healthcare Authority (2013), 'Marktscan en beleidsbrief AWBZ, Weergave van de markt 2010 - 2012', Utrecht.

Eggink, E., M. Ras and I. Woittiez (2017), 'Dutch long-term care use in an ageing population', The Journal of the Economics of Ageing, 9: 63-70.

Galenkamp, H., A. W. Braam, M. Huisman and D. J. Deeg (2012), 'Seventeen-year time trend in poor self-rated health in older adults: changing contributions of chronic diseases and disability', The European Journal of Public Health, 23(3): 511-517.

Gaugler, J. E., S. Duval, K. A. Anderson and R. L. Kane (2007), 'Predicting nursing home admission in the US: a meta-analysis', BMC Geriatrics, 7(1): 1.

Gerace, A. (2012), 'Reposition or wrecking ball: combatting obsolescence in aged nursing home stock', Senior Housing News, http://seniorhousingnews.com/2012/10/24/reposition-orwrecking-ball-combatting-obsolescence-in-aged-nursing-home-stock [20 May 2016].

Grabowski, D. C., K. A. Stewart, S. M. Broderick and L. A. Coots (2008), 'Predictors of nursing home hospitalization a review of the literature', Medical Care Research and Review, 65(1): 3-39.

Grabowski, D. C., A. Elliot, B. Leitzell, L. W. Cohen and S. Zimmerman (2014), 'Who are the innovators? Nursing homes implementing culture change', The Gerontologist, 54(Supplement 1): S65-S75.

Heinen, J., H. Sijsling. and M. Groen (2012), Zorgarchitectuur Zorgvastgoed, Den Haag: Sdu uitgevers.

Hirth, R. A., D. C. Grabowski, Z. Feng, M. Rahman and V. Mor (2014), 'Effect of nursing home ownership on hospitalization of long-stay residents: an instrumental variables approach', International Journal of Health Care Finance and Economics, 14(1): 1-18.

Hoeymans, N., A. Wong, C. H. van Gool, D. J. H. Deeg, W. J. Nusselder, M. M. Y. de Klerk, M.P.J. van Boxtel and H. S. J. Picavet (2012), 'The disabling effect of diseases: a study on trends in diseases, activity limitations, and their interrelationships', American Journal of Public Health, 102: 163-170.

Joldersma, C., M. Laarman-Wierenga and M. Brink (2017), Arbeid in zorg en welzijn 2016, Den Haag: Eindrapport onderzoeksprogramma Arbeidsmarkt Zorg en Welzijn (AZW), CAOP.

Kiers, B. (2016), 'Bewoners verpleeghuizen overlijden steeds sneller', Zorgvisie, 6 October, https://www.zorgvisie.nl/kwaliteit/nieuws/2016/10/bewoners-verpleeghuizen-overlijdensteeds-sneller/ [6 August 2017].

Koren, M. J. (2010), 'Person-centered care for nursing home residents: the culture-change movement', Health Affairs, 29(2): 312-317.

Miller, S. C., V. Mor and J. F. Burgess (2016), 'Studying nursing home innovation: the Green House model of nursing home care', Health Services Research, 51(Supplement 1): 335-343.

Ministry of Health, Welfare and Sport (2013a), 'Wachtlijst langdurige zorg', Letter to Parliament, 24 September 2013.

Ministry of Health, Welfare and Sport (2013b), 'Hervorming van de langdurige ondersteuning en zorg', Letter to the Parliament, 25 April 2013. 
Ministry of Health, Welfare and Sport (2014), 'Memorie van toelichting Wet langdurige zorg', Tweede Kamer, 33891: 3.

Ministry of Health, Welfare and Sport (2015), 'Voortgang Waardigheid en Trots', Letter to the Parliament, 26 June 2015.

Ministry of Health, Welfare and Sport (2016), 'Kwaliteit van Zorg', Letter to the Parliament, 5 July 2016.

Moise, P., M. Schwarzinger and M. Y. Um (2004), 'Dementia care in 9 OECD countries', OECD Working Papers, Paris.

Nouws, H. and L. Sanders (2014), Verzorgingshuis vertimmeren niet altijd noodzakelijk, Den Haag: Kenniscentrum Wonen en Zorg.

OECD (2017), http://www.oecd-ilibrary.org/social-issues-migration-health/data/oecd-health-statis tics/oecd-health-data-long-term-care-resources-and-utilisation_data-00543-en [25 July 2017].

Olde Bijvank, H. M. (2015), 'All inclusive, nieuw en betaalbaar woonserviceproduct in de verzorgingshuizen’, Platform31, Den Haag.

Reschovsky, J. D. (1998), 'The roles of Medicaid and economic factors in the demand for nursing home care', Health Services Research, 33(4 Pt 1): 787-813.

Riedel, M. and M. Kraus (2011), 'The organization of formal long-term care for the elderly: results from the 21 European Country studies in the Ancient project', Enepri Research Report No. 95.

Rothgang, H. (2003), 'Chapter 7. Description of the German long-term care projections model', in A. Comas-Herrera and D. Wittenberg (eds), European Study of Long-Term Care Expenditure, PSSRU Discussion Paper 1840, PSSRU, LSE Health and Social Care, London School of Economics.

Statistics Netherlands (2017a), 'Monitor Langdurige Zorg', http://mlzstatline.cbs.nl/Statweb/ publication $/$ ? $\mathrm{DM}=\mathrm{SLNL} \& \mathrm{PA}=40010 \mathrm{NED} \& \mathrm{D} 1=2 \& \mathrm{D} 2=0 \& \mathrm{D} 3=0 \& \mathrm{D} 4=0-14,1 \& \mathrm{D} 5=$ $0 \& \mathrm{D} 6=8-10 \& \mathrm{HDR}=\mathrm{G} 1, \mathrm{G} 2, \mathrm{G} 4, \mathrm{~T}, \mathrm{G} 5 \& \mathrm{STB}=\mathrm{G} 3 \& \mathrm{VW}=\mathrm{T}$ [25 July 2017].

Statistics Netherlands (2017b), 'Gezonde levensverwachting vanaf 1981', http://statline.cbs.nl/ StatWeb/publication/?VW=T\&DM=SLNL\&PA=71950ned\&LA=NL[26 July 2017].

Statistics Netherlands (2017c), 'Zorginstellingen; financien, personeel, productie en capaciteit 2006-2010', http://statline.cbs.nl/Statweb/publication/?VW=T\&DM=SLNL\&PA=82247 ned \&D1=90,100-101,104-105,125-126\&D2=a\&D3=0-4\&HD=150430-0915\&HDR=T \&STB=G1,G2 [25 July 2017].

Statistics Netherlands (2017d), 'Verpleeghuizen en Verzorgingshuizen; personeel/investering/ instell./exploitatie, 1985-2004', http://statline.cbs.nl/Statweb/dome/?TH=82714\&LA=nl [25 July 2017].

Statistics Netherlands (2017e), 'Prognose bevolking op 1 januari; leeftijd en geslacht, 20122060', http://statline.cbs.nl/Statweb/publication/?DM=SLNL\&PA=81412ned\&D1=a \&D2 $=0 \% 2 \mathrm{c} 129133 \& \mathrm{D} 3=03 \% 2 \mathrm{c} 8 \% 2 \mathrm{c} 13 \% 2 \mathrm{c} 18 \% 2 \mathrm{c} 23 \% 2 \mathrm{c} 28 \% 2 \mathrm{c} 33 \% 2 \mathrm{c} 38 \% 2 \mathrm{c} 43$ $\& \mathrm{HDR}=\mathrm{G} 1 \% 2 \mathrm{cT} \& \mathrm{STB}=\mathrm{G} 2 \& \mathrm{VW}=\mathrm{T}$ [25 July 2017].

Statistics Netherlands (2017f), 'Mediane duur tot overlijden, gebruik en overlijden VV-ZZP', https://www.monitorlangdurigezorg.nl/publicaties/publicaties-2017/mediane-duur-totoverlijden-gebruik-en-indicatie-vv-zzp [26 July 2017].

Stevenson, D. G. and D. C. Grabowski (2010), 'Sizing up the market for assisted living', Health Affairs, 29(1): 35-43.

van Duin, C. and L. Stoeldraijer (2014), 'Projecties van de gezonde levensverwachting tot 2030', CBS, Den Haag.

van Gool, C. H., H. S. J. Picavet, D. J. Deeg, M. M. Y. de Klerk, W. J. Nusselder, M. P. J. van Boxtel, A. Wong and N. Hoeymans (2011), 'Trends in activity limitations: the Dutch older population between 1990 and 2007', International Journal of Epidemiology, 40(4): 1056-1067. 
Werner, R. M., R. T. Konetzka and D. Polsky (2016), 'Changes in consumer demand following public reporting of summary quality ratings: an evaluation in nursing homes'. Health Services Research, 51(S2): 1291-1309.

White-Chu, E. F., W. J. Graves, S. M. Godfrey, A. Bonner and P. Sloane (2009), 'Beyond the medical model: the culture change revolution in long-term care', Journal of the American Medical Directors Association, 10(6): 370-378.

Worrall, P. and T. J. Chaussalet (2015), 'A structured review of long-term care demand modelling', Health Care Management Science, 18(2): 173-194.

Zhao, X. (2016), 'Competition, information, and quality: evidence from nursing homes', Journal of Health Economics, 49: 136-152. 